\title{
Modelling start-up performance of anaerobic digestion of saline-rich macro-algae
}

A. Hierholtzer and J. C. Akunna

CIWA Publishing 2014. The definitive peer-reviewed and edited version of this article is published in Water Science \& Technology 69(10): pp.

2059-2065, 2014, doi: 10.2166/wst.2014.100 and is available at www.iwapublishing.com. 


\section{Water Science and Technology \\ Modelling start-up performance of anaerobic digestion of saline-rich macro-algae \\ --Manuscript Draft--}

\begin{tabular}{|c|c|}
\hline Manuscript Number: & WST-EM13769R2 \\
\hline Full Title: & Modelling start-up performance of anaerobic digestion of saline-rich macro-algae \\
\hline Article Type: & Research Paper (Editorial Office Upload) \\
\hline Keywords: & ADM1; cations; inhibition; laminaria digitata; saline adapted inoculum; sodium \\
\hline Corresponding Author: & $\begin{array}{l}\text { Joseph Akunna, PhD } \\
\text { University of Abertay Dundee } \\
\text { Dundee, UNITED KINGDOM }\end{array}$ \\
\hline \multicolumn{2}{|l|}{$\begin{array}{l}\text { Corresponding Author Secondary } \\
\text { Information: }\end{array}$} \\
\hline Corresponding Author's Institution: & University of Abertay Dundee \\
\hline \multicolumn{2}{|l|}{$\begin{array}{l}\text { Corresponding Author's Secondary } \\
\text { Institution: }\end{array}$} \\
\hline First Author: & A Hierholtzer, PhD \\
\hline \multicolumn{2}{|l|}{ First Author Secondary Information: } \\
\hline \multirow[t]{2}{*}{ Order of Authors: } & A Hierholtzer, PhD \\
\hline & Joseph Akunna, PhD \\
\hline \multicolumn{2}{|c|}{ Order of Authors Secondary Information: } \\
\hline Manuscript Region of Origin: & UNITED KINGDOM \\
\hline Abstract: & $\begin{array}{l}\text { Some of the key factors affecting the adaptation of anaerobic digestion processes to } \\
\text { increasing levels of salinity were determined in batch tests using brown seaweed as a } \\
\text { feedstock. It was found that cultures seeded with non-saline anaerobic inoculum } \\
\text { required an adaptation period of up to two months to reach the same level of methane } \\
\text { production rate as in those cultures seeded with saline adapted inoculum. The } \\
\text { Anaerobic Digestion Model N.1 (ADM1) was modified to include an extra inhibition } \\
\text { function to account for the effect of salinity and calibrated using a set of experimental } \\
\text { data obtained from batch biochemical methane potential tests. After calibration, the } \\
\text { model was able to accurately predict methane production rates. The results thus show } \\
\text { that, in the absence of saline-adapted inoculum, non-saline inoculum can be used for } \\
\text { the start-up of anaerobic digestion systems treating saline-rich feedstocks. }\end{array}$ \\
\hline
\end{tabular}




\title{
Modelling start-up performance of anaerobic digestion of saline-rich macro-algae
}

\author{
A. Hierholtzer*, J. C. Akunna*
}

*Urban Water Technology Centre, School of Science, Engineering \& Technology, University of Abertay Dundee, Bell Street, Dundee DD1 1HG, Scotland, UK

(E-mail: j.akunna@abertay.ac.uk)

\begin{abstract}
Some of the key factors affecting the adaptation of anaerobic digestion processes to increasing levels of salinity were determined in batch tests using brown seaweed as a feedstock. It was found that cultures seeded with non-saline anaerobic inoculum required an adaptation period of up to two months to reach the same level of methane production rate as in those cultures seeded with saline adapted inoculum. The Anaerobic Digestion Model N.1 (ADM1) was modified to include an extra inhibition function to account for the effect of salinity and calibrated using a set of experimental data obtained from batch biochemical methane potential tests. After calibration, the model was able to accurately predict methane production rates. The results thus show that, in the absence of salineadapted inoculum, non-saline inoculum can be used for the start-up of anaerobic digestion systems treating saline-rich feedstocks.
\end{abstract}

\section{Keywords}

ADM1; cations; inhibition; laminaria digitata; saline adapted inoculum; sodium

\section{Introduction}

Anaerobic digestion is a well-developed process involving the use of a microbial consortium to breakdown organic matter, the main outputs being methane and carbon dioxide for the gaseous phase and digestate for the liquid phase. The process can potentially treat all types of organic wastes if favourable conditions are provided for microbial activity. Macro minerals such as sodium, calcium, magnesium or potassium play an essential role in microbial activity and development. These minerals are commonly found in varying concentrations in seawater because of mineral washout and erosion of the earth's crust. They also exist in anaerobic digestion systems as a result of either the breakdown of organic matter or being artificially added for $\mathrm{pH}$ control (Grady et al. 1999). Traces of these nutrients are required in anaerobic systems to stimulate bacterial growth and to ensure process optimisation but too high levels can cause serious microbial inhibition (Chen et al. 2008). Sodium, particularly, can be found in toxic concentrations in digesters treating wastewaters originating from food processing industries (Soto et al. 1993; Feijoo et al. 1995), chemical industries, tanneries or reactors using micro/macro-algae as a substrate.

The methanogenic archaea found in anaerobic reactors are particularly sensitive to sodium concentrations and methanogenesis has been reported to be strongly inhibited at sodium levels exceeding $10 \mathrm{~g} / \mathrm{l}$ (Lefebvre and Moletta 2006). Accumulation of sodium ions in anaerobic systems can bring about excessive increase in the osmotic pressure regulating the water flow across the cell membrane which can lead to cell death (Ollivier et al. 1994). Some authors have reported relatively high accumulation of propionate and acetate in anaerobic systems receiving saline feedstock, indicating that high salinity levels may have a greater impact on the acetogenic bacteria and acetoclastic methanogens than on acidogens (Rinzema et al. 1987). Different inhibitory 
concentrations of sodium have been reported by various authors, also suggesting that the level of microbial sodium inhibition may be dependent on factors such as system design, operation, and seed inoculum. Soto et al. (1993) reported that a sodium ions concentration ranging between 14 to $18 \mathrm{~g} / \mathrm{l}$ can reduce methanogenic activity by up to $50 \%$ ( $\left.\mathrm{IC}_{50}\right)$. With granular sludge, Rinzema et al. (1987) found an $\mathrm{IC}_{50}$ value of about $10 \mathrm{gNa}^{+} / 1$ whilst Feijoo et al. (1995) reported an $\mathrm{IC}_{50}$ of 16.3 $\mathrm{gNa}^{+} / 1$ with saline-adapted seed inoculum. It has also been reported that the use of anaerobic reactor sludge bed fitted with microfiltration membrane systems can increase the $\mathrm{IC}_{50}$ to an even higher value of up to $25 \mathrm{gNa}^{+} / 1$ (Jeison et al. 2008).

Some microorganisms can tolerate or adapt to a relatively high sodium induced osmotic pressure by accumulating other inorganic ions within their cells which ensures osmotic balance with the saline medium thus preventing sodium from reaching their cytoplasm (Oren 2002). This may result in reduced microbial inhibitory effects of sodium as observed in cultures containing other cations such as $\mathrm{Ca}^{2+}, \mathrm{Mg}^{2+}$ and $\mathrm{K}^{+}$(Appels et al. 2008; Chen et al. 2008). In contrast, some microorganisms which occur naturally in highly-saline environments require sodium chloride for growth and are categorised as moderately to extremely halophilic according to the level of salt requirement (Ollivier et al. 1994). Since the latter, depending on their halophilic category, require certain amounts of salt for their metabolic activities, their use in wastewater treatment may only be limited to wastewaters with the requisite and less variable salt content (Aspé et al. 1997).

It can therefore be assumed that halophilic anaerobic microorganisms will be more effective for treating saline rich feedstocks, whilst saline-adapted anaerobic microorganisms will adapt more readily in systems treating feedstocks containing fluctuating salt levels (as often is the case in anaerobic digestion systems receiving diverse types of organic materials). There has been very little literature on the effect of variable level of salts in anaerobic systems treating feedstocks which are classified as non saline-rich such as sewage treatment plant sludge, agricultural and food/beverage residuals, despite the fact that some of these feedstocks can sometimes contain elevated levels of salts usually brought about by operational practices such as effluent recycling, $\mathrm{pH}$ control with sodium hydroxide and co-digesting with saline-rich feedstocks like marine biomass (Hierholtzer and Akunna 2012). The aim of this study is therefore to investigate the major factors affecting the adaptation of anaerobic systems treating non-saline rich feedstocks to variable levels of salinity using both experimental and modelling approaches.

\section{Materials and methods \\ Experimental approach}

The aim of the experimental approach was to determine the effects of various levels of feedstock salinity on both saline adapted and non-saline anaerobic digestion cultures.

\section{Inoculum and feedstock}

The experiment was carried out in batch, using two types of inoculum: mesophilic anaerobically digested sewage sludge as non-saline inoculum and anaerobic digestate from a laboratory scale mesophilic anaerobic digester treating seaweed as saline-adapted inoculum. The sodium level in the latter was about $15 \mathrm{~g} \mathrm{Na}^{+} / 1$. The non-saline inoculum was obtained from a municipal mesophilic anaerobic digester (Hatton, Angus, UK) treating domestic wastewater sludges containing an average of $0.2 \mathrm{~g} \mathrm{Na}^{+} / 1$. Both sources of inoculum have been in operation for more than 2 years prior to the commencement of this study. Brown seaweed (Laminaria digitata), a saline-rich feedstock, was collected from the Westhaven beach $\left(56^{\circ} 30^{\prime} \mathrm{N}, 2^{\circ} 42^{\prime} \mathrm{W}\right)$ near Dundee, Scotland, UK in October 2010. The seaweed was washed after collection to remove debris and sand, oven-dried at about $75^{\circ} \mathrm{C}$ for 24 hours and milled in an industrial blender to obtain a particle size of about $1 \mathrm{~mm}$. The dried and milled sample was then stored in sealed containers at room temperature.

\section{Design of batch assays}


Batch tests were designed to determine the effect of varying levels of salinity on the kinetic cultures were obtained by mixing the prepared feedstock sample and inoculum with either seawater or freshwater. Four sets of batch test cultures were used for the study. The first set consisted of culture bottles $\left(\mathrm{A}_{\mathrm{na}}\right)$, each containing $400 \mathrm{ml}$ of non-saline inoculum, 10 grams of the prepared seaweed, and $90 \mathrm{ml}$ of freshwater. The second set of culture bottles $\left(\mathrm{B}_{\mathrm{na}}\right)$, was similar to the first set, except that $90 \mathrm{ml}$ of seawater, instead of freshwater, was added to each bottle. The third $\left(A_{a}\right)$ and fourth $\left(B_{a}\right)$ sets of culture bottles were similar to $A_{n a}$ and $B_{n a}$ respectively, except that salineadapted inoculum replaced the non-saline inoculum. The chemical oxygen demand (COD), total solids (TS) and volatile solids (VS) concentrations of seaweed diluted with freshwater were 66.8 $\mathrm{g} / \mathrm{l}, 88.2 \mathrm{~g} / \mathrm{l}$ and $21.2 \mathrm{~g} / \mathrm{l}$ respectively; and $73.2 \mathrm{~g} / \mathrm{l}, 119.3 \mathrm{~g} / \mathrm{l}$ and $34.4 \mathrm{~g} / \mathrm{l}$ respectively for seaweed diluted with seawater. All the test cultures were set in duplicates. The bottles were closed with rubber caps, degassed with nitrogen gas and incubated at mesophilic temperature $\left(37^{\circ} \mathrm{C} \pm 1^{\circ} \mathrm{C}\right)$ for 50 days. Blanks test cultures containing only inoculum were also incubated alongside the test cultures. To avoid overpressure in the bottles, gas release was carried out routinely by displacement of a syringe piston and the amount of methane gas released was added to cumulative biogas production. Methane production rate was used as the overall indicator parameter. Ultimate methane yields were determined based on the method of Hansen et al. (2004).

\section{Analytical methods}

Methane production was measured by gas chromatography using a Hewlett-Packard 5890 Series II gas chromatograph with dual thermal conductivity detector and an AT-Alumina stainless steel capillary column. Injector, oven and detector temperatures were $120^{\circ} \mathrm{C}, 50^{\circ} \mathrm{C}$ and $150^{\circ} \mathrm{C}$ respectively and helium was used as a carrier gas. Gas samples were collected in a gas tight syringe and $100 \mu$ of sample was transferred to the gas chromatograph. Methane yield results were converted to standard temperature and pressure (STP: $273.15^{\circ} \mathrm{K} ; 1013.25 \mathrm{hPa}$ ). Total and volatile solids were determined based on standard methods (APHA 1992). Total volatile fatty acids (VFA) were quantified by esterification (Montgomery et al. 1962) and colorimetric determination using a DR5000 spectrophotometer (Hach-Lange, USA). Cations concentrations were measured by flame emission spectroscopy with a Flame Photometer 400 (Ciba-Corning, USA) for sodium, calcium and potassium and by using an atomic absorber AAnalyst 200 (Perkin-Elmer, USA) for magnesium. COD was measured using Hach-lange cuvette tests (LCK 014) and samples were centrifuged for the determination of soluble COD. Concentration of ammonium nitrogen was determined by cuvette tests (LCK 304).

\section{Modelling approach}

The aim of the modelling approach was to predict the effects of various levels of salinity on the rate of methane production based on the data obtained from the batch experiments.

\section{Model modifications}

The implementation of the ADM1 in Matlab/Simulink (MathWorks Inc., USA) carried out by Rosen and Jeppsson (2006) is used as a platform in this study. Sodium inhibition has been reported to affect mainly the acetate utilizers or acetoclastic methanogens, by lowering their maximum specific growth rate and yield (Rinzema et al. 1987; Feijoo et al. 1995). The original structure of the ADM1 is such that inhibition of acetate utilizers will adversely affect the overall production of methane since acetate is also produced partly from the oxidation of reduced compounds which includes butyric and propionic acids. Hence, implementing an extra inhibition to the rate of acetate uptake can be used to represent the effect of sodium inhibition. Methane production resulting from hydrogenofil methanogenic bacteria might however be overestimated by the model but it is assumed that this pathway is significantly less important than the acetic-methane pathway since 
more than two thirds of methane produced during anaerobic digestion comes from the latter found in the original model and expressed as in equation (1).

$$
I_{\text {acetate }}=I_{p H, a c} \cdot I_{I N, \text { lim }} \cdot I_{N_{3}} \cdot I_{\text {cations }}
$$

Where $I_{\text {acetate }}$ is the overall inhibition function applied to the rate of acetate uptake, $I_{p H, a c}$ is the $\mathrm{pH}$ inhibition function, $I_{I N, \text { lim }}$ is the inorganic nitrogen inhibition function, $I_{N H 3}$ is the ammonia nitrogen inhibition function, $I_{\text {cations }}$ is a non-competitive function taking into consideration the effect of cations concentration not represented in the original ADM1 model. $I_{\text {cations }}$ can be expressed as shown in equation (2).

$$
I_{\text {cations }}=\frac{1}{1+\left(\frac{S_{\mathrm{Na}^{+}}}{K_{I, \mathrm{Na}^{+}}}\right)+\left(\frac{S_{\mathrm{Mg}^{2+}}}{K_{I, \mathrm{Mg}^{2+}}}\right)+\left(\frac{S_{\mathrm{Ca}^{2+}}}{K_{I, C a^{2+}}}\right)+\left(\frac{S_{K^{+}}}{K_{I, \mathrm{~K}^{+}}}\right)}
$$

Where $S_{\mathrm{Na}}{ }^{+}, S_{\mathrm{Mg}}{ }^{2+}, S_{\mathrm{Ca}}{ }^{2+}$, and ${S_{K}}^{+}$are the concentrations of sodium, magnesium, calcium and potassium respectively found in the system. $K_{I, N a}{ }^{+}, K_{I, M g}{ }^{2+}, K_{I, C a}{ }^{2+}$, and $K_{I, K}{ }^{+}$are the inhibitory concentrations of sodium, magnesium, calcium and potassium respectively for acetate degrading organisms.

The function, $I_{\text {cations, }}$, considers that all cations present in saline water have an inhibitory effect on acetoclastic methanogens when found above their respective $K_{I}$ values. In seawater cations are typically found in ratios of $0.122,0.039$ and 0.037 for $\mathrm{Mg}^{2+} / \mathrm{Na}^{+}, \mathrm{K}^{+} / \mathrm{Na}^{+}$, and $\mathrm{Ca}^{2+} / \mathrm{Na}^{+}$respectively (Jeison et al. 2008) and sodium is found at inhibitory levels before other cations reach their respective inhibitory concentrations. The function is thus valid at cations ratios commonly found in seawater but could be modified if the individual effects of high concentrations of magnesium, calcium or potassium need to be considered. To take into account possible synergism where the presence of $\mathrm{Ca}^{2+}, \mathrm{Mg}^{2+}$ and $\mathrm{K}^{+}$contributes to the reduction of sodium toxicity, a different function could be implemented to decrease the value of the inhibition factor applied to acetate uptake. However, this approach was discarded because it would only be valid if the level of synergism towards sodium inhibition can be experimentally estimated for each group of cations, both individually and as a group. This estimation was not carried out in this study. The parameter $S_{C A T}$ is originally implemented in the ADM1 to represent metallic ions such as $\mathrm{Na}^{+}$, and can be estimated by the measurement of alkalinity. Sodium, calcium, magnesium and potassium cations were hence not added directly in the charge balance but $S_{C A T}$ was adjusted appropriately to obtain the correct simulation for $\mathrm{pH}$ within the model. This modelling approach has been shown to enable model users to obtain satisfying predictions when cation concentrations are not measured individually (Hierholtzer and Akunna 2012). The concentrations of each of the cations can be calculated using equation (3) used individually for $\mathrm{Na}^{+}, \mathrm{Ca}^{2+}, \mathrm{Mg}^{2+}$ and $\mathrm{K}^{+}$.

$\frac{d S_{\text {Cations }}}{d t}=\frac{q_{\text {in }}}{V_{\text {liq }}}\left(S_{\text {Cations sin }}-S_{\text {cations }}\right)$

Where $q_{i n}$ is the reactor inflow, $V_{\text {liq }}$ the effective capacity of the reactor. $S_{\text {Cations }}$ and $S_{\text {Cations,in }}$ being the initial concentrations of the different cations in the system and in the feedstock respectively. The degree of acclimatisation of the inoculum used was considered here to impact on the inhibitory sodium concentration tolerated by acetate degrading organisms and on their maximum specific uptake rate $\left(K_{m, a c}\right)$. By adjusting the values of $K_{I, N a}^{+}$and $K_{m, a c}$ it was possible to represent the 
adaptation of the microbial consortium to sodium over time in the model without specific

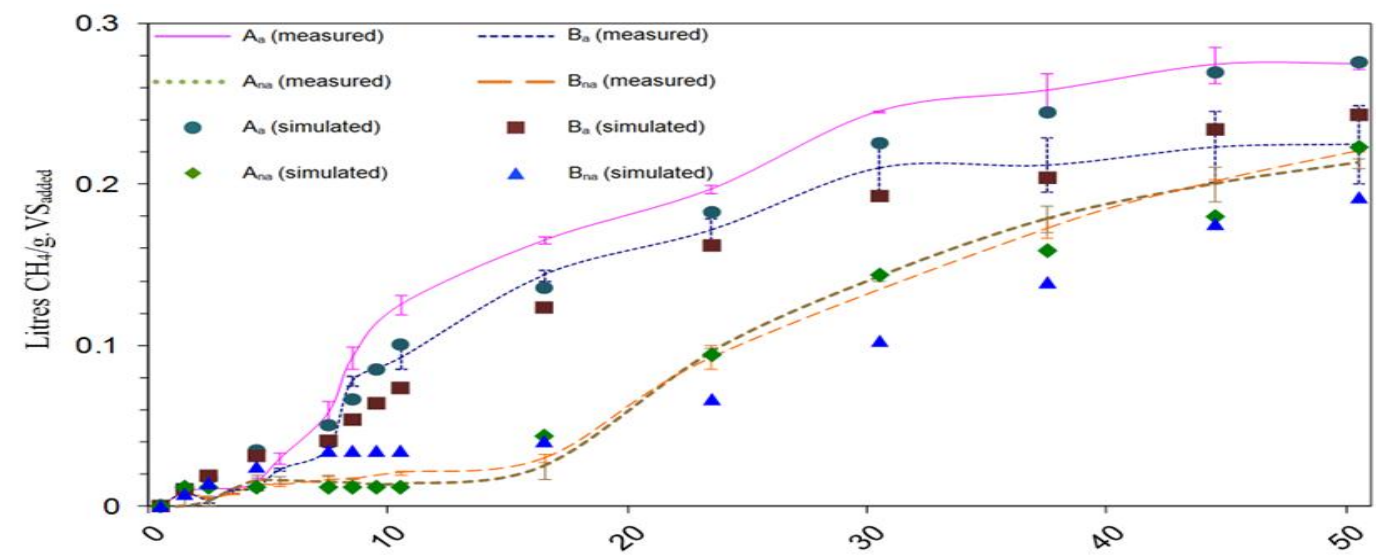

Figure 1. Experimental and simulated cumulative Yyethane production in cultures seeded with nonsaline $\left(A_{n a}, B_{n a}\right)$ and saline-adapted $\left(A_{a}, B_{a}\right)$ inocula, and diluted with freshwater $\left(A_{n a}, A_{a}\right)$ and seawater $\left(\mathrm{B}_{\text {na }}, \mathrm{B}_{\mathrm{a}}\right)$.

\begin{tabular}{|c|c|c|c|c|c|c|c|}
\hline \multirow{2}{*}{ Sample } & \multicolumn{4}{|c|}{ Cations concentrations (g/L) } & \multicolumn{3}{|c|}{ Cations ratios } \\
\hline & $\mathrm{Na}^{+}$ & $\mathrm{Ca}^{2+}$ & $\mathrm{Mg}^{2+}$ & $\mathrm{K}^{+}$ & $\mathrm{Na}^{+} / \mathrm{Ca}^{2+}$ & $\mathrm{Na}^{+} / \mathrm{Mg}^{2+}$ & $\mathrm{Na}^{+} / \mathrm{K}^{+}$ \\
\hline $\mathrm{A}_{\text {na }}$ (freshwater) & 1.22 & 0.08 & 0.24 & 1.23 & 15.25 & 5.08 & 0.99 \\
\hline $\mathrm{A}_{\mathrm{a}}$ (freshwater) & 13.67 & 0.48 & 0.49 & 2.26 & 28.48 & 27.90 & 6.05 \\
\hline $\mathrm{B}_{\mathrm{na}}$ (seawater) & 5.51 & 0.2 & 0.49 & 1.31 & 27.55 & 11.24 & 4.21 \\
\hline $\mathrm{B}_{\mathrm{a}}$ (seawater) & 14.87 & 0.52 & 0.97 & 2.34 & 28.60 & 15.33 & 6.35 \\
\hline
\end{tabular}

\section{Results and discussion \\ Experimental results}

The experimental and simulated cumulative methane production for all the cultures net of blank results is shown in Figure 1. The cultures seeded with non-saline inoculum, $A_{n a}$ and $B_{n a}$, produced relatively small amounts of methane in the first 15 days. The delay in methane production observed for these cultures is believed to be due the process of acclimatisation when the microorganisms were adapting to the higher salt concentration of the culture. After the lag period, the methane increased gradually and eventually reached the same levels as those produced in cultures seeded with saline-adapted inoculum, $A_{a}$ and $B_{a}$. It can also be seen from the figure that, for cultures diluted with freshwater $\left(A_{n a}, A_{a}\right)$, methane production rate was higher in cultures seeded with saline-adapted inoculum, $A_{a}$, than in those seeded with non-saline inoculum $A_{\text {na }}$. For seawaterdiluted cultures $\left(\mathrm{B}_{\mathrm{na}}, \mathrm{B}_{\mathrm{a}}\right)$, there was no significant difference between the methane produced by both types of inocula at the end of the experiment. Table 1 shows the different cations concentrations and their ratios in the cultures. It can be seen that the saline-adapted cultures $\left(A_{a}, B_{a}\right)$ contained relatively high salt concentrations indicating that the addition of freshwater or seawater had little impact on overall salt levels. The similarity in methane production obtained from $B_{n a}$ and $B_{a}$ cultures (and to some extent, $A_{n a}$ and $A_{a}$ ) despite the significant differences in their total salt content, shows that microbial adaptation plays a major role in effective digestion of saline-rich feedstock. 
For cultures seeded with saline-adapted inoculum $\left(\mathrm{A}_{\mathrm{a}}, \mathrm{B}_{\mathrm{a}}\right)$, it was assumed that biodegradation using least square curve fitting of the measured cumulative methane production. Ultimate methane yields were estimated to be 0.332 and $0.289 \mathrm{~L}^{-\mathrm{CH}_{4}} / \mathrm{gVS}_{\text {added, }}$, and methane production rate constants 0.055 and $0.061 \mathrm{~d}^{-1}$ for $A_{a}$ and $B_{a}$ respectively. These values were similar to those reported in literature for laminaria digitata which ranged between 0.26-0.29 litres $\mathrm{CH}_{4} / \mathrm{gVS}_{\text {added }}$ (Carpentier $e t$ al. 1988; Chynoweth et al. 1993). Non-saline adapted cultures $\left(\mathrm{A}_{\text {na }}, \mathrm{B}_{\text {na }}\right)$ were not considered to follow first-order kinetics during the acclimatisation period which covered the first 15 days. Beyond Day 15, biodegradation in these cultures was considered to follow first order kinetics. Subsequently, ultimate methane yields were estimated to be 0.212 and $0.221 \quad \mathrm{~L} . \mathrm{CH}_{4} / \mathrm{gVS}_{\text {added }}$, and methane production rate constants 0.034 and $0.032 \mathrm{~d}^{-1}$ for $\mathrm{A}_{\mathrm{na}}$ and $\mathrm{B}_{\mathrm{na}}$ respectively.

These results thus show that in the absence of saline-adapted inoculum, non-saline cultures can be successfully used for the start-up of a digester treating moderately saline feedstocks, although, depending on the operational parameters (hydraulic retention time, organic loading rate, etc) a variable adaptation period would be required before achieving optimum performance.

\section{Modelling results \\ Influent characterisation and model stoichiometric parameters}

The ADM1 requires a careful influent characterisation together with accurate fractionating of intermediates, namely: proteins, carbohydrates, lipids and soluble inerts. Parameters $f_{p r, x c}, f_{c h, x c}, f_{l i, x c}$, $f_{s i, x c}$ and $f_{x i, x c}$ were estimated from the average composition of the laminaria digitata seaweed used in the study. First order parameters corresponding to the hydrolysis kinetic rates of carbohydrates, lipids and proteins were set at similar rates since their influence is not significant for homogenous substrates (Feng et al. 2006). $K_{h y d, c h,} K_{h y d, p r}, K_{h y d, l i}$ were calibrated from the cumulative production of methane obtained after the 50-day test duration and taken equal to $1.2 \mathrm{~d}^{-1}$. The feedstock characterisation was carried out using the transformer model elaborated by Zaher et al. (2009), which transforms a set of practical measurements to the input vector required by the ADM1. The concentrations of sodium, potassium, magnesium, and calcium were adjusted from measured values shown in Table 1. The maximum uptake rate for acetate $\left(K_{m, a c}\right)$ was adjusted from fitting simulation results to experimental results for VFA and methane production, and the values obtained were $17 \pm 0.82 \mathrm{kgCOD} . \mathrm{kgCOD}^{-1} \mathrm{~d}^{-1}$ and $7.83 \pm 1.55 \mathrm{kgCOD} . \mathrm{kgCOD}^{-1} \mathrm{~d}^{-1}$ for saline-adapted and non-saline cultures respectively. The much lower value obtained for the non-saline inoculum was due to the relatively long period of acclimatisation observed in these cultures as shown in Figure 1. Increasing the half saturation value of acetate users was not considered since it has been reported that different pairs of $K_{m} / K_{s}$ could yield similar simulation results, since both parameters are mathematically dependant and cannot be calibrated simultaneously (Girault et al. 2011). Hence the values of $K_{m}$ used in this study were valid only when $K_{s}$ was set at its default value $\left(0.02\right.$ day $\left.^{-1}\right)$. Similarly, the $50 \%$ inhibitory concentration for sodium was estimated from experimental results to be $0.11 \pm 0.009$ $\mathrm{kmol} / \mathrm{m}^{3}$ and $0.61 \pm 0.005 \mathrm{kmol} / \mathrm{m}^{3}$ for non-saline and saline adapted microorganisms respectively. Inhibition values for other cations were taken from literature reports, $K_{I, M_{g}}{ }^{2+}=0.06 \mathrm{kmol} / \mathrm{m}^{3}$ (Appels et al. 2008), $K_{I, C a}{ }^{2+}=0.12 \mathrm{kmol} / \mathrm{m}^{3}$ (Ahn et al. 2006) and $K_{I, K}{ }^{+}=0.15 \mathrm{kmol} / \mathrm{m}^{3}$ (Kugelman and McCarty 1965). Initial values for inorganic carbon $\left(S_{I C}\right)$, inorganic nitrogen $\left(S_{I N}\right)$, and cations concentrations $\left(S_{C A T}\right)$ were obtained from experimental results. All other parameters were taken equal to the values used by Rosen and Jeppsson (2006).

\section{Simulation results}

Figure 2 shows the correlation between the final methane productions (expressed in normalised $\mathrm{ml}$ $\mathrm{CH}_{4} /$ batch) predicted by the modified ADM1 and measured values. A good fit was obtained between the results of the modified model and the experimental data and the model correctly predicted the lag phase observed in some of the experimental tests as shown in Figure 1. The high 
correlation coefficients, ranging from 0.925 to 0.985 , are indicative of the validity of the modelling approach and variables estimation method used in this study.

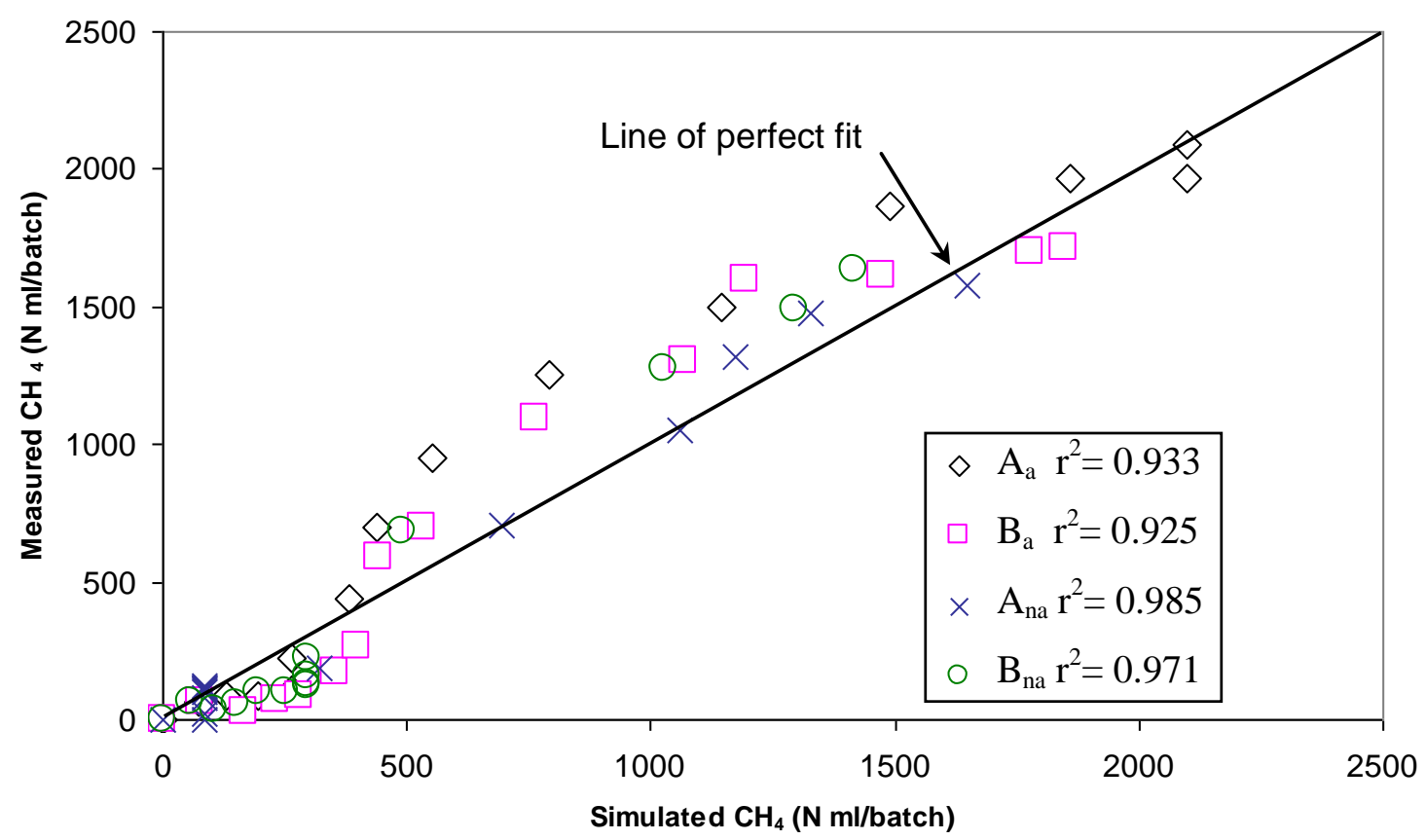

Figure 2. Comparison between experimental and modified ADM1 model results for methane production in cultures seeded with non-saline $\left(A_{n a}, B_{n a}\right)$ and saline-adapted $\left(A_{a}, B_{a}\right)$ inocula, and diluted with freshwater $\left(A_{n a}, A_{a}\right)$ and seawater $\left(B_{n a}, B_{a}\right)$.

Following calibration, the modified model can thus be used to determine the effect of increasing salinity on methane production and assist in the operation of anaerobic digesters treating feedstocks with varying salt concentrations. The modifications presented in this work are valid when sodium is found at inhibitory levels before other cations reach their respective inhibitory concentrations and do not consider synergism or antagonism effects with other light metal cations and the impact on microorganisms.

\section{Conclusions}

The research has shown that non-saline-adapted anaerobic sludge can effectively be used in the start-up of anaerobic digestion systems treating saline enriched feedstocks, following an appropriate period of adaptation, which depends on initial salt concentration and other operational parameters. The study also showed that the adaption period can be modelled using a modified ADM1 model and parameter estimation methodology.

\section{Acknowledgments}

This work has been funded by the University of Abertay Dundee. The authors wish to express their gratitude to Dr. Ulf Jeppsson and Dr. Christian Rosen for providing their Matlab code of ADM1.

\section{References}

Ahn, J., Do, T.H., Kim, S.D. and Hwang, S. 2006. The effect of calcium on the anaerobic digestion treating swine manure. Biochemical Engineering Journal 30, 33-38.

APHA 1992. Standard Methods for the Examination of Water and Wastewater. 18th edition, American Public Health Association, American Water Works Association, Water Environment Federation, Washington D.C.

Appels, L., Baeyens, J., Degrève, J. and Dewil, R. 2008. Principles and potential of the anaerobic digestion of waste-activated sludge. Progress in Energy and Combustion Science 34, 755-781. 
Aspé, E., Marti, M.C. and Roeckel, M. 1997. Anaerobic treatment of fishery wastewater using a marine sediment inoculum. Water Research 31(9), 2147-2160.

Batstone, D.J., Pind, P.F. and Angelidaki, I. 2003. Kinetics of thermophilic, anaerobic oxidation of straight and branched chain butyrate and valerate. Biotech. Bioeng. 84(2), 195-204.

Carpentier, B., Festino, C. and Aubart, C. 1988. Anaerobic digestion of flotation sludges from the alginic acid extraction process. Biological Wastes 23, 269-278.

Chen, Y., Cheng, J. and Creamer, K.S. 2008. Inhibition of anaerobic digestion process: A review. Bioresource Technology 99, 4044-4064.

Chynoweth, D.P., Turick, C.E., Owens, J.M., Jerger, D.E. and Peck, M.W. 1993. Biochemical methane potential of biomass and waste feedstocks. Biomass and Bioenergy 5, 95-111.

Feijoo, G., Soto, M., Méndez, R. and Lema, J.M. 1995. Sodium inhibition in the anaerobic digestion process: Antagonism and adaptation phenomena. Enzyme and Microbial Technology 17, 180-188.

Feng, Y., Behrendt, J., Wendland, C. and Otterpohl, R. 2006. Parameter analysis of the IWA Anaerobic Digestion Model No.1 for the anaerobic digestion of blackwater with kitchen refuse. Water Science \& Technology 54(4), 139-147.

Girault, R., Rousseau, P., Steyer, J.P., Bernet, N. and Béline, F. 2011. Combination of batch experiments with continuous reactor data for ADM1 calibration: application to anaerobic digestion of pig slurry. Water Science \& Technology 63(11), 2575-2582.

Grady, C.P.L., Daigger, G.T. and Lim, H.C. 1999. Biological Waste Water Treatment. $2^{\text {nd }}$ Edition, Marcel Dekker, New York.

Hansen, T.L., Schmidt, J.E., Angelidaki, I., Marca, E., la Cour Jansen, J., Mosbæk, H. and Christensen, T.H. 2004. Method for determination of methane potentials of solid organic waste. Waste Management 24, 393-400.

Hierholtzer, A. and Akunna, J.C. 2012. Modelling sodium inhibition on the anaerobic digestion process. Water Science \& Technology 66(7), 1565-1573.

Jeison, D., Kremer, B. and van Lier, J.B. 2008. Application of membrane enhanced biomass retention to the anaerobic treatment of acidified wastewaters under extreme saline conditions. Separation and Purification Technology 64, 198-205.

Kugelman, I.J. and McCarty, P.L. 1965. Cation toxicity and stimulation in anaerobic waste treatment. Journal of the Water Pollution Control Federation 37(1), 97-116.

Lefebvre, O. and Moletta, R. 2006. Treatment of organic pollution in industrial saline wastewater: A literature review. Water Research 40, 3671-3682.

Montgomery, H.A.C., Dymock, J.F. and Thom, N.S. 1962. The rapid colorimetric determination of organic acids and their salts in sewage-sludge liquor. The Analyst 87, 949-955.

Ollivier, B., Caumette, P., Garcia, J.L. and Mah, R.A. 1994. Anaerobic Bacteria from Hypersaline Environments. Microbiological Reviews 58, 27-38.

Oren, A. 2002. Intracellular salt concentrations and ions metabolism in halophilic microorganisms. In: Oren, A. (ed.) Halophilic Microorganisms and their Environments. Dordrecht, Kluwer Academic Publishers, 207-232.

Pohland, F.G. 1992. Anaerobic treatment: fundamental concepts, applications, and new horizons. In: Malina, J.F. and Pohland, F.G. (eds.) Design of Anaerobic Processes for the Treatment of Industrial and Municipal Wastes, vol. 7. Lancaster, CRC Press, 1-33.

Rinzema, A., van Lier, J. and Lettinga, G. 1987. Sodium inhibition of acetoclastic methanogens in granular sludge from a UASB reactor. Enzyme Microb. Technol. 10, 24-32.

Rosen, C. and Jeppsson, U. 2006. Description of the ADM1 for benchmark simulations. Technical Report, Department of Industrial electrical Engineering and Automation (IEA), Lund University, Lund: Sweden.

Soto, M., Mendez, R. and Lema, J.M. 1993. Sodium inhibition and sulphate reduction in the anaerobic treatment of mussel processing wastewaters. J. Chem. Technol. Biotechnol. 58, 1-7.

Zaher, U., Buffiere, P., Steyer, J.P. and Chen, S. 2009. A procedure to Estimate Proximate Analysis of Mixed Organic Wastes. Water Environment Research 81(4), 407-415. 